\title{
Синтез InGaN-наноструктур развитой морфологии на кремнии: влияние температуры подложки на морфологические и оптические свойства
}

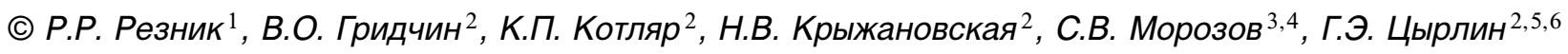 \\ ${ }^{1}$ Университет ИТМО, \\ 197101 Санкт-Петербург, Россия \\ ${ }^{2}$ Санкт-Петербургский Академический университет, \\ 194021 Санкт-Петербург, Россия \\ ${ }^{3}$ Институт фризики микроструктур Российской академии наук, \\ 603950 Нижний Новгород, Россия \\ ${ }^{4}$ Нижегородский государстенный университет им. Н.И. Лобачевского, \\ 603950 Нижний Новгород, Россия \\ ${ }^{5}$ Институт аналитического приборостроения Российской академии наук, \\ 190103 Санкт-Петербург, Россия \\ ${ }^{6}$ Санкт-Петербургский государственный электротехнический университет „ЛЭТИ“, \\ 197376 Санкт-Петербург, Россия \\ E-mail: moment92@mail.ru
}

Поступила в Редакцию 15 апреля 2020 г.

В окончательной редакции 21 апреля 2020 г.

Принята к публикации 21 апреля 2020 г.

Исследована зависимость морфологических характеристик и оптических свойств InGaN-наноструктур разветвленной морфологии на поверхности $\mathrm{Si}(111)$ от температуры подложки при выращивании методом молекулярно-пучковой эпитаксии. Показано, что при увеличении температуры подложки увеличивается высота наноколонн InGaN, формирующихся на начальном этапе роста. Увеличение температуры роста InGaN-наноструктур также приводит к увеличению интенсивности спектров фотолюминесценции от таких структур, причем зависимости интегральной интенсивности фотолюминесценции от плотности мощности возбуждения являются линейными. Эти факты указывают на перспективность структур для оптических приложений, в частности для создания белых светодиодов на основе единого материала.

Ключевые слова: наноструктуры, InGaN, кремний, молекулярно-пучковая эпитаксия, полупроводники, оптоэлектроника.

DOI: $10.21883 /$ FTP.2020.09.49826.18

\section{1. Введение}

B настоящее время InGaN вызывает повышенный интерес как материал для создания твердотельных источников света видимого диапазона [1] и возобновляемых источников энергии [2] благодаря тому, что является прямозонным полупроводником и имеет ширину запрещенной зоны, варьируемую от 0.7 до 3.43 эВ в зависимости от доли индия в твердом растворе [3]. Однако по причине отсутствия собственных подложек синтез высококачественных эпитаксиальных слоев InGaN затруднителен в силу значительного различия постоянных решеток и коэффициентов термического расширения между InGaN и другими полупроводниковыми материалами, что является причиной возникновения высокой плотности дефектов различной природы в слоях InGaN. Вместе с тем существенное различие межатомных расстояний в $\mathrm{InN}$ и $\mathrm{GaN}$ приводит к образованию разрыва смешиваемости при содержании In $\sim 0.4-0.6$ в объемном InGaN $[4,5]$. Одним из решений данных проблем является синтез непланарных InGaN-наноструктур. Благодаря развитой морфологии механические напряжения в полупроводниковых нано- структурах, вызванные различием постоянных решеток, коэффициентов термического расширения и явлением разрыва смешиваемости [6], релаксируют и количество дефектов значительно уменьшается [7]. В предыдущей работе [8] нами была показана принципиальная возможность синтеза InGaN-наноструктур разветвленной морфологии на неподготовленной поверхности $\mathrm{Si}(111)$. Было показано, что для синтезированных наноструктур характерны спектры фотолюминесценции (ФЛ) вплоть до комнатной температуры в широком диапазоне длин волн, зависимость интегральной интенсивности ФЛ от плотности мощности возбуждения является линейной.

В данной работе представлены результаты исследований влияния температуры подложки при молекулярнопучковой эпитаксии (МПЭ) на физические свойства InGaN-наноструктур развитой морфологии, синтезированных на поверхности кремния.

\section{2. Экспериментальные методы}

Эксперименты по синтезу InGaN-наноструктур развитой морфологии проводились с помощью установки 


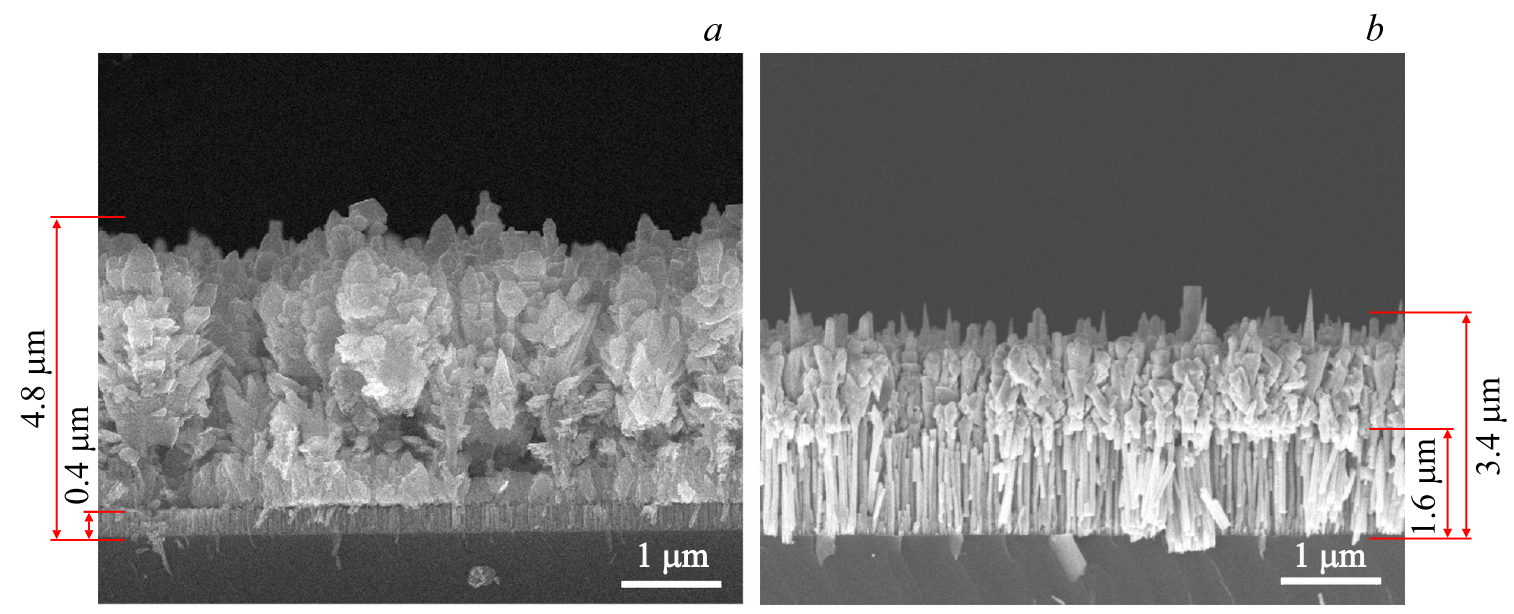

Рис. 1. Типичные РЭМ-изображения InGaN-наноструктур развитой морфологии, выращенных при температуре подложки $T_{s}$ : $a-600^{\circ} \mathrm{C}[8], b-630^{\circ} \mathrm{C}$.

МПЭ Riber Compact 12, оснащенной эффузионными источниками индия $(\mathrm{In})$, галлия $(\mathrm{Ga})$ и плазменным источником азота. В рамках данной работы были синтезированы два образца, различающиеся между собой только температурой подложки во время роста $\left(T_{s}\right)$. Синтез InGaN-наноструктур осуществлялся по методике, описанной в работах $[8,9]$. На первом этапе загруженные в ростовую камеру подложки $\mathrm{Si}(111)$ р-типа проводимости нагревались до $950^{\circ} \mathrm{C}$ для термической очистки. После этого температуру подложки понижали до ростовой: $600^{\circ} \mathrm{C}$ для одного образца и $630^{\circ} \mathrm{C}$ для второго. Температура подложек во время ростового процесса не изменялась. Потоки галлия и индия при синтезе InGaNнаноструктур были равны между собой и составляли $1 \cdot 10^{-7}$ Торр. Рост каждого образца длился 19 ч.

Исследования морфологических свойств синтезированных InGaN-наноструктур проводились с помощью растрового электронного микроскопа (РЭМ) Supra 25 Zeiss. Исследования оптических свойств синтезированных наноструктур проводились с помощью метода ФЛ при комнатной температуре. В качестве возбуждения использовалась вторая гармоника (400 нм) фемтосекундного лазера „Tsunami“ фирмы Spectra-Physics (800 нм, 120 фс, 80 МГц). Сигнал ФЛ измерялся с помощью спектрометра „Acton TriVista“ и регистрировался CCD-камерой фирмы Princeton Instruments. Кинетика ФЛ регистрировалась с помощью стрик-камеры „Optoscop“ фирмы Optronis.

\section{3. Результаты и обсуждение}

На рис. 1, $a, b$ представлены типичные РЭМ-изображения InGaN-наноструктур развитой морфологии, выращенных при температурах подложки $T_{s}=600$ и $630^{\circ} \mathrm{C}$ на $\mathrm{Si}(111)$. Как видно из рисунка, повышение температуры подложки приводит к уменьшению средней высоты структуры от 4.8 до 3.4 мкм. Уменьшение вы- соты InGaN-наноструктур при повышении температуры подложки может быть обусловлено увеличением десорбции атомов с поверхности образца и изменением морфологии растущей структуры. В связи с меньшей энергией связи In $-\mathrm{N}$ по сравнению с $\mathrm{Ga}-\mathrm{N}$ следует предположить, что с поверхности происходит десорбция адатомов индия. Как и в случае синтеза при $T_{s}=600^{\circ} \mathrm{C}$, при температуре подложки $630^{\circ} \mathrm{C} \mathrm{InGaN-наноструктуры}$ развитой морфологии формируются в несколько этапов. Тем не менее в случае более высокотемпературного роста наблюдается увеличение высоты наноколонн, формирующихся на первом этапе. Исходя из соображений разности энергий связи индия и галлия с азотом логично предположить, что доля $\mathrm{Ga}$ в наноколоннах выше, чем In. На следующем этапе происходит трехмерный рост $\mathrm{InGaN}$-наноструктур развитой морфологии. Увеличение высоты наноколонн подтверждает предположение о том, что изменение морфологии InGaN-наноструктур происходит по причине уменьшения эффективной температуры на поверхности образца $[8,10,11]$.

На рис. 2, а представлены спектры ФЛ синтезированных образцов при комнатной температуре. Спектр ФЛ образца, выращенного при $T_{s}=600^{\circ} \mathrm{C}$, располагается в широком диапазоне длин волн от 450 до 950 нм, как было показано в работе [8]. Спектр ФЛ InGaN-наноструктур, синтезированных при более высокой температуре, при комнатной температуре занимает диапазон длин волн от 450 до 800 нм. По-видимому, при повышенной температуре подложки встраивание индия в структуру в целом меньше, чем при более низкой температуре эпитаксии. Более узкая линия ФЛ может свидетельствовать о меньших флуктуациях состава твердого раствора InGaN. При этом интегральная интенсивность ФЛ от таких структур в $\sim 3$ раза больше, чем от InGaN-наноструктур, синтезированных при $600^{\circ} \mathrm{C}$, что указывает на более высокое кристаллическое качество наноструктур. Максимум спектра ФЛ от наноструктур, выращенных 

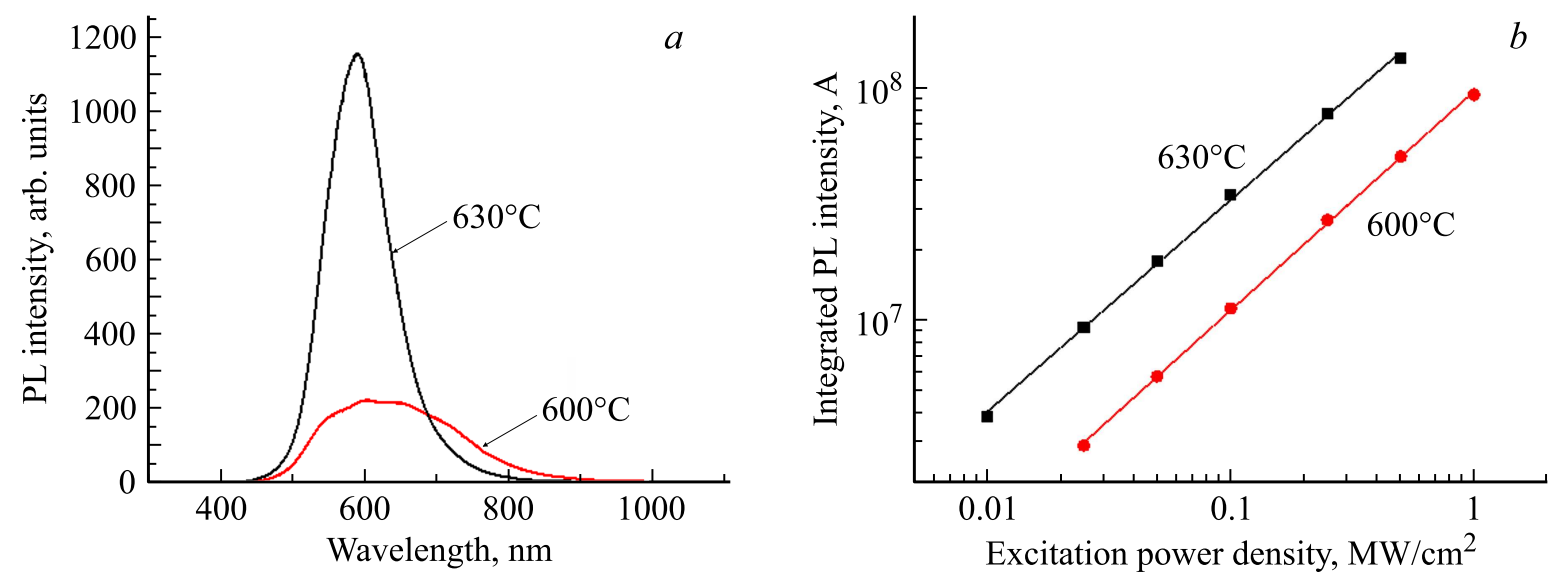

Pис. 2. $a-$ спектры фотолюминесценции (PL) при комнатной температуре InGaN-наноструктур развитой морфологии, выращенных при температурах подложки $T_{s}=600^{\circ} \mathrm{C}[8]$ и $630^{\circ} \mathrm{C} . b-$ зависимости интегральных интенсивностей фотолюминесценции $(\mathrm{PL})$ от плотности мощности возбуждения для InGaN-наноструктур, выращенных при температурах подложки $T_{s}=600[8]$ и $630^{\circ} \mathrm{C}$; точки - экспериментальные данные, линии - результат линейных аппроксимаций.

при $T_{s}=630^{\circ} \mathrm{C}$, соответствует длине волны $590 \mathrm{Hм}$ (2.102 эВ). В соответствии с законом Вегарда [12] средняя доля In в твердом растворе $\operatorname{In}_{x} \mathrm{Ga}_{1-x} \mathrm{~N}$ с шириной запрещенной зоны 2.102 эВ составляет $x=0.45$. Такой состав находится внутри диапазона разрыва смешиваемости для $\mathrm{InGaN}$.

На рис. 2, $b$ представлены зависимости интегральной интенсивности ФЛ выращенных наноструктур от плотности мощности накачки. Как видно из рисунка, зависимости описываются линейной функцией вида $f=k x+b$, где $k \approx 0.95$ для $T_{s}=600^{\circ} \mathrm{C}$ и $k \approx 0.91$ для $T_{s}=630^{\circ} \mathrm{C}$. Коэффициент наклона, близкий к 1 , свидетельствует о слабой роли безызлучательной рекомбинации в структурах. Важно отметить, что интегральная интенсивность ФЛ от InGaN-наноструктур, синтезированных при более высокой температуре, значительно больше, чем интегральная интенсивность наноструктур, выращенных при $600^{\circ} \mathrm{C}$.

\section{4. Заключение}

Таким образом, в данной работе исследована зависимость морфологических и оптических свойств InGaNнаноструктур разветвленной морфологии на поверхности $\mathrm{Si}(111)$ от температуры подложки в процессе выращивания методом МПЭ. Показано, что увеличение температуры подложки приводит к изменению морфологии InGaN-наноструктур. В частности, увеличивается высота InGaN-наноколонн, формирующихся на начальном этапе роста. Такое изменение морфологии наноструктур подтверждает сделанное в предыдущей работе предположение о том, что изменение морфологии InGaN-наноструктур происходит по причине уменьшения эффективной температуры на поверхности образца. Исследования оптических свойств показали, что увеличение температуры роста InGaN-наноструктур приводит к увеличению интенсивности спектров ФЛ от таких структур. Важно отметить, что зависимости интегральной интенсивности ФЛ от мощности возбуждения являются линейными для обоих образцов. Все эти факты в совокупности с интервалом их оптического излучения указывают на перспективность таких структур для оптических приложений - например, для создания белых светодиодов на основе одного материала.

\section{Финансирование работы}

Работа была выполнена при финансовой поддержке Министерства науки и высшего образования Российской Федерации (RFMEFI61619X0115).

\section{Конфликт интересов}

Авторы заявляют, что у них нет конфликта интересов.

\section{Список литературы}

[1] T.D. Moustakas, E. Iliopoulos, A.V. Sampath, H.M. Ng, D. Doppalapodi, M. Misra, D. Korakakis, R. Singh. J. Cryst. Growth, 227, 13 (2001).

[2] J. Li, J.Y. Lin, H.X. Jiang. Appl. Phys. Lett., 93 (16), 162107 (2008).

[3] F.K. Yam, Z. Hassan. Superlatt. Microstr., 43 (1), 23 (2008).

[4] I. Ho, G.B. Stringfellow. Appl. Phys. Lett., 69 (18), 2703 (1996).

[5] M. Lopez, M. Auf der Maur, A. Pecchia, F. Sacconi, G. Penazzi, A. Di Carlo. IEEE, 113 (2013).

[6] H.J. Xiang, W. Su-Huai, J.L.F. Da Silva, L. Jingo. Phys. Rev. B, 78 (19), 193301 (2008).

[7] V.G. Dubrovskii, G.E. Cirlin, V.M. Ustinov. Semiconductors, 43 (12), 1539 (2009).

[8] R.R. Reznik, K.P. Kotlyar, N.V. Kryzhanovskaya, S.V. Morozov, G.E. Cirlin. Tech. Phys. Lett., 45 (11), 1113 (2019). 
[9] R.R. Reznik, K.P. Kotlyar, I.V. Il'kiv, I.P. Soshnikov, S.A. Kukushkin, A.V. Osipov, E.V. Nikitina, G.E. Cirlin. Phys. Solid State, 58 (10), 1952 (2016).

[10] F. Glas, J.-C. Harmand. Phys. Rev. B, 73 (15), 155320 (2006).

[11] N.V. Sibirev, I.P. Soshnikov, V.G. Dubrovskii, E. Arshansky. Tech. Phys. Lett., 32 (4), 292 (2006).

[12] A.R. Denton, N.W. Ashcroft. Phys. Rev. A, 43 (6), 3161 (1991).

Редактор Л.В. Шаронова

\section{Synthesis of branched InGaN nanostructures on silicon: the influence of substrate temperature on morphological and optical properties}

R.R. Reznik ${ }^{1}$, V.O. Gridchin ${ }^{2}$, K.P. Kotlyar ${ }^{2}$, N.V. Kryzhanovskaya ${ }^{2}$, S.V. Morozov ${ }^{3,4}$, G.E. Cirlin ${ }^{2,5,6}$

${ }^{1}$ ITMO University,

197101 St. Petersburg, Russia

2 Alferov University, 194021 St. Petersburg, Russia

${ }^{3}$ Institute for Physics of Microstructures, Russian Academy of Sciences, 603950 Nizhny Novgorod, Russia ${ }^{4}$ Lobachevsky State University of Nizhny Novgorod, 603950 Nizhny Novgorod, Russia

5 Institute for Analytical Instrumentation, Russian Academy of Sciences, 190103 St. Petersburg, Russia ${ }^{6}$ St. Petersburg Electrotechnical University „LETI", 197376 St. Petersburg, Russia

Abstract In this work, the influence of substrate temperature on morphological and optical properties of branched InGaN nanostructures on the $\mathrm{Si}(111)$ surface during MBE growth was studied. It was shown that an increase of the substrate temperature leads to a change in the morphology of InGaN nanostructures. In particular, the height of InGaN nanocolumns, which are formed at the initial stage of growth, increases. At the same time, an increase in the growth temperature of $\mathrm{InGaN}$ nanostructures leads to an increase in the intensity of the photoluminescence spectra from such structures, and the dependences of the integrated photoluminescence intensity on the excitation power are linear in both cases. All these facts indicate the promise of such structures for optical applications, for example, for creating white LEDs based on a single material. 